\title{
Determination of joint roughness coefficient (JRC) for slope stability analysis : A case study from the Gold Coast area, Australia
}

\author{
Dong-Hyun Kim \\ Ivan Gratchev
}

Aramugan Balasubramaniam

\author{
Griffith School of Engineering, Griffith University, Australia \\ Griffith School of Engineering, Griffith University, Australia \\ Griffith School of Engineering, Griffith University, Australia
}

\section{Abstract}

Surface roughness of rock discontinuities is an important factor that determines the strength characteristics of rock mass. Joint roughness coefficient (JRC), which is typically measured by means of Barton's combs in the field, is widely used to describe the joint roughness. However, this traditional method of measurement can be rather subjective, labor-intensive and time consuming. In contrast, photogrammetry can provide an alternative method to obtain relatively simple and fast measurements of JRC based on high resolution 3D models. However, the reliability of such measurements still remains an issue as the results from photogrammetry can be affected by the quality of images. This study seeks to clarify whether photogrammetry can produce accurate measurements of JRC that can be used to assess the stability of slopes. A rock slope with a recent wedge failure in the Gold Coast area, Australia was selected for this purpose, and three different methods such as manual measurements, photogrammetry, and tilt tests were employed to determine the JRC. The obtained results showed some discrepancy in the values of JRC obtained from these three different measurements. In particular, the JRC obtained using the Barton's comb had slightly higher values compared to those determined through the photogrammetry method while the tilt test results tended to yield overestimated values of JRC. Computer analysis using UDEC was also performed to study the effect of JRC variation on the slope stability. It was found that an increase in the JRC led to an increase in the safety factor of the slope.

Keywords: rock slope, photogrammetry, stability analysis, joint roughness coefficient

\section{Introduction}

Joint roughness coefficient (JRC) has been widely used in rock slope stability analysis since it was developed by Barton and Choubey (1977). JRC is traditionally estimated by comparing the surface of discontinuities with typical roughness profiles (Barton et al. 1977). However, this mapping process is rather labor-intensive and typically associated with significant risks during field works. In addition, manual measurements tend to be rather subjective leading to overestimation (Grasselli 2003; Milne 2009). To address this problem, remote sensing techniques such as photogrammetry can be utilized to greatly reduce the time of surveys, and minimize the risk involved. Although it is a relatively new technique, it has already been applied to characterize the slope geometry, providing vital information for the slope stability assessment (Ferrero et al. 2011; Firpo et al. 2011; Brideau et al. 2012). High resolution 3D-digital models derived from this method can also produce JRC values of slope discontinuities (Haneberg 2007; Poropat 2009). Guo et al. (2011) demonstrated that photogrammetry can 
successfully map and characterize the type and geometry of rock discontinuities using high resolution digital images. However, the reliability of JRC values obtained from photogrammetry can still be an issue as it greatly depends on the quality of images, and an error can occur due to the spatial density of data (Haneberg 2007).

This study seeks to assess the accuracy of JRC values obtained from 3-D models and the effect of JRC variation on slope stability analysis. To achieve this goal, field investigation, including photogrammetry survey, was performed at a natural slope in the Tambourine mountain area of the Gold Coast, Australia where a recent failure occurred due to heavy rainfall. The location and size of this rock slope enabled a range of measurements from manual determination of JRC to the application of photogrammetry. Laboratory examination of rock samples, including point load and tilt tests, was performed to study the strength characteristics of rocks and discontinuities. Finally, JRC values obtained from manual measurements, tilt tests and photogrammetry were compared, and the effect of JRC variation on the slope stability was examined using a computer code "UDEC". This paper presents and discusses the obtained results.

\section{Determination of JRC}

Three methods of JRC measurements were employed in this study to determine the effect of surface roughness on the slope stability. Each of them is briefly described below.

\section{Field measurements using Barton's combs}

A standard method of JRC determination is related to field measurements, which are performed using a profile gauge (for example, Barton's comb). An example of such measurements is given in Fig. 6 and will be discussed in detail later. JRC values, which vary from 0 to 20 , are obtained through the comparison of the measured joint surface geometry with the one presented in the Barton's standard profile chart (Barton and Choubey 1977). Although this method seems to produce reliable measurements of the rock surface roughness, it is rather laborintensive and time-consuming. In addition, due to the technical and safety reasons, this method can't be applied to large slopes.

\section{Tilt tests}

A tilt test is a simple and relatively fast method to estimate the shear strength parameters of discontinuities. Barton and Choubey (1977) proposed to utilize the results of this test to estimate the JRC of rock samples. In this test, two pieces of rock containing a discontinuity in between them are slowly tilted until the top block moves (Fig.1). The angle with the horizontal at onset of movement is called the tilt-angle. The tilt angle is then used to calculate the JRC of the rock surface as shown in Eq. 1.

$J R C=\frac{\alpha-\emptyset_{\mathrm{r}}}{\log _{10}\left(\frac{\mathrm{JCS}}{\sigma_{\mathrm{no}}}\right)}$

(1)

where, $\alpha$ : tilt angle, $\sigma_{\mathrm{n}}:$ normal stress, $\sigma_{\mathrm{n}}$ : normal stress acting on the joint, JCS : joint wall compressive strength, and $\phi_{\mathrm{r}}$ : residual friction angle. JCS values can be estimated using Schmidt hammer tests, while the residual friction angle can be defined using Eq. 2. 
$\emptyset_{r}=\left(\emptyset_{b}-20^{\circ}\right)+20\left(\frac{r}{R}\right)$

(2)

where $\phi_{\mathrm{b}}$ : basic friction angle, $\mathrm{r}$ : rebound number of the weathered joint wall (saturated), and $\mathrm{R}$ : rebound no. of dry, unweathered surfaces of the rock.

Although this method provides a simple and relatively fast way to measure the JRC, the obtained results can be rather subjective as the size of rock samples are limited to $30 \mathrm{~cm}$ lenghwise.

\section{Photogrammetry method}

Recent studies by Haneberg (2007) and Poropat (2009) demonstrated that photogrammetry can be successfully used to describe the joint surface roughness. Figure 2 shows an example of the roughness profile obtained from a 3-D model created by the Sirovision computer code. Sirovision calculates the JRC based on the empirical relationships by Maertz (1990) and Tse and Cruden (1979). Tse and Cruden (1979) suggested statistical approach to Barton and Choubey's standard joint surface profiles (Eq.3,4).

$$
\begin{aligned}
& \mathrm{JRC}=32.2+32.47 \log \mathrm{Z}_{2} \\
& \mathrm{JRC}=37.28+16.58 \log \mathrm{SF}
\end{aligned}
$$

where, $Z_{2}$ is the root mean square while SF is the mean square of the first derivative of the profile.

Maerz et al. (1990) proposed to estimate JRC using a regression equation that describes the relationship between JRC and the roughness profile index, $R_{p}$. This roughness profile index $\left(R_{p}\right)$ is defined as the ratio of the true length of a fracture surface trace to its projected length in the fracture plane.

$\mathrm{JRC}=411\left(\mathrm{R}_{\mathrm{p}}-1\right)$

where, $R_{p}$ is the roughness profile index measured by photo analysis.

\section{Field investigation}

\section{Geology of the study area}

Field investigation was performed at a slope cut along the Beaudesert-Nerang Road that connects the Gold Coast with the Tambourine Mountain area (Fig. 3a). The length of this slope was about $200 \mathrm{~m}$ with a height varying from 8-10 m (Fig. 3b). This slope has experienced slope stability problems in the past few years, especially during long periods of rain.

The geology of the site (Fig. 3a) is comprised of argillite and sandstone of the Neranleigh-Fernvale Beds (Willmott, 2010; Shokouhi et al., 2013). The rocks were heavily weathered, folded and steeply inclined. Argillite, which is hardened and slightly recrystalized shale, was fine-grained rock, bedding, and fractured in many exposures (Fig. 3b). The sandstone was mostly coarse-grained sediment of dark grey color.

\section{Strength characteristics of rocks}

The in-situ strength characteristics of the rocks were determined by performing 70 Schmidt hammer tests at different parts of the slope. The results of these tests were correlated to the unconfined compressive strength (UCS) using empirical relationships proposed by Katz et al. (2000), and Yasar and Erdogan (2004). The data 
presented in Table 1 indicate that the average UCS values for the argillite and sandstone were about 19.3 MPa and 13.1 MPa, respectively.

Although Schmidt hammer tests provide a good indication of the rock strength, they are often considered least reliable as they yield a large scatter of values. For this reason, several rock samples were collected for laboratory examination. A series of point load tests were performed on representative samples of sandstone and argillite following the Australian standard (AS 4133). The obtained results plotted in Fig. 4 against the corresponding values of UCS indicate that the strength of sandstone was about 6.2 MPa while the mean value of UCS for the argillite was $17.7 \mathrm{MPa}$. Such relatively low values of UCS can be attributed to the high degree of weathering of these rocks.

A series of tilt tests were also performed to obtain the tilt angle of rock samples with discontinuities. Sandstone with a size of 10-15 cm lengthwise was collected from the face of the slope near the failure area. The obtained results indicated that the tilt angle of sandstone was in the range of $49-58^{\circ}$.

\section{Photogrammetry survey}

\section{Data collection and georeferencing}

Data on the rock surface characteristics such as the orientation of discontinuities, joint spacing and JRC were obtained using the photogrammetry method. A professional Nikon camera (model D7000) and lens of $24 \mathrm{~mm}$ focal length were used to photograph three different sections of the slope. Each section was photographed from two points, with the distance between the camera positions being equal from 1/8 to 1/6 the distance from the camera to the slope (CSIRO, 2005). Georeferencing was performed for each photo by determining the coordinates of the left camera position (using a GPS device), and measuring its bearing (azimuth) to the centre of slope (using a geological compass) (Sturzenegger, 2010). After 3D-models were built for each slope section (Fig. 5a) using the "Sirovision" computer code, mapping of the major slope features, including discontinuities, were performed as shown in Fig. 5b. The size of blocks, type and characteristics of discontinuities including dip and dip direction were identified and recorded.

\section{Verification of 3D models}

To establish whether the photogrammetry technique can produce accurate measurements of joint orientations, Gratchev et al. (2013) compared the values of dip and dip direction of discontinuities obtained by a geological compass and photogrammetry. Gratchev et al. (2013) noted that although a small error existed, it did not have a significant impact on the results. In the present study, a few control points (red circles in Fig. 6a) were also used to determine the potential of photogrammetry to produce accurate measurements. Table 2 presents the results of such tests in which the distance between the control points was measured manually (by a ruler) and using the 3D models (by means of sirovision). It is evident from Table 2 that only a marginal error exists between these two types of measurements, suggesting that the photogrammetry method can produce reliable results.

\section{Determination of JRC using photogrammetry}

After the reliability of 3D models in producing accurate measurements was confirmed, JRC values of the joint 
surfaces were obtained using the Maerz et al. (1990) and Tse and Cruden (1979) approaches. Surface roughness profiles of three selected sections were extracted from the 3D models at four different directions (dip direction, and $45^{\circ}, 90^{\circ}, 135^{\circ}$ to the dip direction). $30 \mathrm{JRC}$ values were calculated on blocks of $30-50 \mathrm{~cm}$ at different locations as shown in Fig. 7 to study the overall distribution of JRC in the slope. Figure 8 summarizes the obtained data, indicating that the mean value of JRC was 5.4 (using the Maerz relationship) and 6.5 (using the Tse and Cruden relationship).

\section{Application of JRC to slope stability analysis}

\section{JRC values obtained through different methods}

Table 3 summarizes the JRC values obtained from a) photogrammetry method (Maerz, and Tse and Cruden relationships), b) manual measurements (Barton's comb), and c) tilt test results. It is evident from this table that the JRC obtained using the Barton's comb (manual measurements) has slightly higher values compared to those determined through the photogrammetry method. However, the difference between the JRC increases when the measuring planes differ from the plane of the dip (the steepest decent). Figure 9 indicates that the overall shape of the profiles extracted from the 3D model is consistent with the manual measurement. However, it was found that the surface roughness profiles obtained from the manual measurements were more detailed, providing more precise values of JRC. This difference can be attributed to the resolution of digital images as a higher resolution can produce larger number of points and thus more precise surface profiles (Haneberg, 2007). Guo et al. (2011) noted that the resolution of digital images needs to be increased to ensure the reliability of JRC values using photogrammetry.

The tilt tests produced the JRC values which were much higher than those obtained by manual measurements and photogrammetry, especially for sections 1 and 2 of the slope. This difference can be attributed to the small size of rock samples used in the tilt tests. However, it is interesting to note that for relatively high values of JRC (section 3), the results obtained from three different methods are similar, especially for the plane with the steepest decent.

\section{Slope stability analysis using JRC}

To study the effect of JRC on the slope stability, the failure mechanism of the slope was analyzed by means of the Universal Distinct Element Code (UDEC). The joint spacing, dip and dip directions of major discontinuities were obtained from the 3-D model. The cross-section of the slope was determined based on the near slope geometry. Three different JRC values obtained from the manual measurement, photogrammetry and tilt tests as well as the results from field (Schmidt hammer) and laboratory (point load) tests were used to determine the joint strength properties (Table 4). The Coulomb-slip model was utilized to describe three major joint sets as show in Fig. 10. Joint shear stiffness $\left(\mathrm{K}_{\mathrm{s}}\right)$ was calculated using the equation (6) (Barton and Choubey 1977), and the joint normal stiffness was estimated by assuming the $\mathrm{K}_{\mathrm{n}} / \mathrm{K}_{\mathrm{s}}$ ratio to 3 . Table 4 summarizes the properties of rocks and rock joints adopted for the numerical analyses.

$K_{S}=\frac{100}{L_{x}} \sigma_{n} \tan \left[J R C \log _{10}\left(\frac{J C S}{\sigma_{n}}\right)+\emptyset_{r}\right]$ 
(6)

where $\mathrm{K}_{\mathrm{s}}$ : joint shear stiffness $\left(\mathrm{MN} / \mathrm{m}^{2} / \mathrm{m}\right), \mathrm{L}_{\mathrm{x}}$ : joint length in meters.

The obtained results indicated that the slope was unstable (the safety factor (SF) was less than 1) for all three values of JRC. However, it was found that an increase in the JRC resulted in an increase in SF (Table 5). The numerical analysis also demonstrated that the thickness of the sliding mass increased as the JRC dropped from 8.0 to 5.4 (Fig. 11).

\section{Conclusions}

In this paper, JRCs obtained from three different methods were compared and their effect on the stability of a rock slope was assessed. Based on the obtained results, the following conclusions can be drawn:

- Photogrammetry can provide JRC values which are similar to those obtained from field measurements using a Barton's comb.

- JRC values obtained from the tilt tests were significantly greater than those obtained from the manual measurements and photogrammetry. However, when the JRC increased from 5.4 to 8 , this difference became negligible.

- $\quad$ Results of slope stability analysis indicated that the JRC had a significant influence on the safety factor; that is, when the JRC increased the safety factor of the slope also increased.

\section{Acknowledgement}

The work was supported by the NRG grant from Griffith University, Australia. The authors with to thank Mr. George Poropat from CSIRO and Professor Douglas Stead from Simon Fraser University in Canada for valuable helps, and Mr. Ali Shokouhi for assistance in field investigation and data analysis.

\section{Reference}

AS 4133.4.1 (2007) Method 4.1 : Rock strength tests - Determination of point load strength index

Barton N, Choubey V (1977) The Shear Strength of Rock Joints in Theory and Practice. Rock Mech 10 : 1-54

Brideau M-A, Sturzenegger M, Stead D, Jaboyedoff M, Lawrence M, Roberts N, Ward B, Millard T, Clague J (2012) Stability analysis of the 2007 Chehalis lake landslide based on long-range terrestrial photogrammetry and airborne LiDAR data. Landslides 9 : 75-91

CSIRO Exploration and Mining (2005) Field procedures for photogrammetric pit mapping

Ferrero AM, Migliazza M, Roncella R, Rabbi E (2011) Rock slopes risk assessment based on advanced geostructural survey techniques. Landslides $8: 221-231$

Firpo G, Salvini R, Francioni M, Ranjith PG (2011) Use of digital terrestrial photogrammetry in rocky slope stability analysis by Distinct Elements Numerical Methods. Int J Rock Mech Min Sci 48 : 1045-1054

Grasselli G, Egger P (2003) Constitutive law for the shear strength of rock joints based on three-dimensional surface parameters. Int J Rock Mech Min Sci 40 : 25-40

Gratchev I, Shokouhi A, Kim DH, Stead D, Wolter A (2013) Assessment of rock slope stability using remote sensing technique in the Gold coast area, Australia. 18th Southeast Asian Geotechnical \& Inaugural AGSSEA Conference 
Guo H, Karekal S, Poropat G, Soole P, Lambert C (2011) Pit wall strength estimation with 3D imaging. CSIRO, ACARP

Haneberg WC (2007) Directional roughness profiles from three-dimensional photogrammetric or laser scanner point clouds. $1^{\text {st }}$ Canada-U.S. Rock Mechanics Symposium, Vancouver : 101-106

Itasca (2011) UDEC v.5.0. Itasca Consulting Group, Minneapolis

Katz O, Reches Z, Roegiers J-C (2000) Evaluation of mechanical rock properties using a Schmidt Hammer. Int J Rock Mech Min Sci 37 : 723-728

Maerz NH, Franklin JA, Bennett CP (1990) Joint roughness measurement using shadow profilometry. Int J

Rock Mech Min Sci 27 : 329-343

Milne D, Hawkes C, Hamilton C (2009) A new tool for the field characterization of joint surfaces. Proc the $3^{\text {rd }}$ CANUS Rock Mechanics Symposium, Toronto

Poropat GV (2009) Measurement of Surface Roughness of Rock Discontinuities. Proc the $3^{\text {rd }}$ CANUS Rock Mechanics Symposium, Toronto

Shokouhi A, Gratchev I, Kim DH (2013) Rock slope stability problems in Gold Coast area, Australia. Int J GEOMATE vol 4 no $1: 501-504$

Sturzenegger M (2010) Multi-scale characterization of rock mass discontinuities and rock slope geometry using terrestrial remote sensing techniques. PhD thesis, Simon Fraser University

Tse R, Cruden DM (1979) Estimating joint roughness coefficients. Int J Rock Mech Min Sci 16 : 303-307

Willmott W (2010) Rocks and landscape of the Gold Coast hinterland. Geological society of Australia, Queensland division

Yasar E, Erdogan Y (2004) Estimation of rock physiomechanical properties using hardness methods. Eng Geol $71: 281-288$ 
Fig 1. Tilt test on sandstone

Fig 2. Joint roughness profile created using 3-D models

Fig 3. Geological map (a) and a photo (b) of the study area

Fig 4. Relationship between unconfined compressive strength (UCS) and point load strength for sandstone and argillite

Fig 5. A 3-D model of slope section (a) and mapping of major geological structures (b)

Fig 6. Manual measurement of joint roughness profiles using a Barton's comb between the control points (a) and obtained joint roughness profiles (b)

Fig 7. Roughness profile extraction using the 3-D model

Fig 8. Results of JRC measurements using photogrammetry

Fig 9. Comparison of roughness profiles between 3-D models and manual measurement (Barton's comb)

Fig 10. Schematic profiles of slope used for numerical modeling

Fig 11. Results of computer analysis using UDEC : Displacement magnitude (a) JRC=5.4 (b) JRC=8.0, Displacement vector (c) JRC $=5.4$ (d) JRC $=8.0$ 